Int. J. Electrochem. Sci., 11 (2016) $4988-5008$

\title{
Treatment of Brewery Wastewater with Electrocoagulation: Improving the Process Performance by Using Alternating Pulse Current
}

\author{
Murat Eyvaz \\ Department of Environmental Engineering, Gebze Technical University, 41400 Kocaeli, Turkey \\ E-mail: $\underline{\text { meyvaz@gtu.edu.tr }}$
}

doi: $10.20964 / 2016.06 .11$

Received: 24 February 2016 / Accepted: 23 March 2016 / Published: 4 May 2016

The main aim of this study is to investigate the technical and economic feasibility of electrocoagulation process on the treatment of brewing industry effluents. Effects of current type on process performance were also stated with a batch operated electrocoagulation reactor including four plate electrodes. Two electrode materials, Fe and Al, were separately employed in parallel connection. A low-moderate strength brewery wastewater was selected as wastewater and model electrolyte solution. Direct current power supply with an adjustable time relay by which rectangular wave was produced was combined with sacrificial electrodes. Performance of the electrocoagulation process was analyzed in terms of operating parameters such as, $\mathrm{pH}$, current density, operating time, electrode material, and current type with removal efficiencies, only some of which were presented in figures and others were given in tables due to the numbers of parameters. Both electrode materials exposed similar pollutant removal performances while Al electrode was found cost effective one. However, alternating pulse current was found superior to direct current, namely, it provided higher removal rates in shorter operating times.

Keywords: Electrocoagulation, Brewery wastewaters, Direct current; Alternating current; Alternating pulse current

\section{$\underline{\text { FULL TEXT }}$}

(C) 2016 The Authors. Published by ESG (www.electrochemsci.org). This article is an open access article distributed under the terms and conditions of the Creative Commons Attribution license (http://creativecommons.org/licenses/by/4.0/). 